\title{
Extracellular plasma RNA from colon cancer patients is confined in a vesicle-like structure and is mRNA-enriched
}

\author{
JOSÉ MIGUEL GARCÍA, ${ }^{1,4}$ VANESA GARCÍA, ${ }^{1,4}$ CRISTINA PEÑA, ${ }^{1}$ GEMMA DOMÍNGUEZ, ${ }^{1}$ JAVIER SILVA, \\ RAQUEL DIAZ, ${ }^{1}$ PABLO ESPINOSA, ${ }^{1}$ MARIA JESÚS CITORES, ${ }^{2}$ MANUEL COLLADO, ${ }^{3}$ and FÉLIX BONILLA ${ }^{1}$ \\ ${ }^{1}$ Department of Medical Oncology, Hospital Universitario Puerta de Hierro, E-28035 Madrid, Spain \\ ${ }^{2}$ Department of Tumor Immunology, Hospital Universitario Puerta de Hierro, E-28035 Madrid, Spain \\ ${ }^{3}$ Tumor Suppression Group, Spanish National Cancer Centre (CNIO), E-28029 Madrid, Spain
}

\begin{abstract}
Little is yet known about the origin and protective mechanism of free nucleic acids in plasma. We investigated the possibility of these free nucleic acids being particle associated. Plasma samples from colon cancer patients and cell culture media were subjected to various antibody incubations, ultracentrifugation, and RNA extraction protocols for total RNA, epithelial RNA, and mRNA. Flow cytometry using a Ber-EP4 antibody and confocal laser microscopy after staining with propidium iodide were also performed. mRNA levels of the $L I S C H 7$ and SDHA genes were determined in cells and in culture media. Ber-EP4 antibody and polystyrene beads coated with oligo dT sequences were employed. We observed that, after incubation, total RNA and mRNA were always detected after membrane digestion, and that epithelial RNA was detected before this procedure. In ultracentrifugation, mRNA was caught in the supernatant only if a former lysis mediated or in the pellet if there was no previous digestion. Flow cytometry determinations showed that antibody-coated microbeads keep acellular structures bearing epithelial antigens apart. Confocal laser microscopy made 1- to 2- $\mu$ m-diameter particles perceptible in the vicinity of magnetic polystyrene beads. Relevant differences were observed between mRNA of cells and culture media, as there was a considerable difference in LISCH7 mRNA levels between HT29 and IMR90 cell co-cultures and their culture media. Our results support the view that extracellular RNA found in plasma from cancer patients circulates in association with or is protected in a multiparticle complex, and that an active release mechanism by tumor cells may be a possible origin.
\end{abstract}

Keywords: vesicle-like structures; plasma mRNA; colon cancer

\section{INTRODUCTION}

The presence of extracellular nucleic acids in human plasma or serum is well established (Mandel and Métais 1948), but real interest in this field began in the 1960s with the detection of DNA in the serum of patients with Systemic Lupus Erythematosus (Tan et al. 1966; Koffler et al. 1973). Later studies demonstrated abnormal quantities of plasma

\footnotetext{
${ }^{4}$ These authors contributed equally to this work.

Abbreviations: Ab, antibody; DEE, Dynabeads Epithelial Enrich; DMEM, Dulbecco modified Eagle medium; FCS, fetal calf serum; FITC, fluorescein isothiocyanate; LISCH7, liver-specific bHLH-Zip transcription factor; PBS, phosphate-buffered saline; PCR, polymerase chain reaction; PE, phycoerytrin; PI, propidium iodide; QRT-PCR, real-time PCR; RT, room temperature; SDHA, succinate dehydrogenase complex subunit A.

Reprint requests to: Félix Bonilla, Department of Medical Oncology, Hospital Universitario Puerta de Hierro, C/ San Martín de Porres, 4, E-28035 Madrid, Spain; e-mail: fbonilla.hpth@salud.madrid.org; fax: 34-91-3445189.

Article published online ahead of print. Article and publication date are at http://www.rnajournal.org/cgi/doi/10.1261/rna.755908.
}

DNA in patients suffering from various autoimmune disorders and other inflammatory conditions (Leon et al. 1981; Fournie et al. 1993), as well as in patients with benign gastrointestinal processes (Shapiro et al. 1983). Finally, DNA was also found in patients with diverse types of cancer and in normal healthy subjects, but in higher quantities in cancer patients (Leon et al. 1977). Qualitative studies have shown alterations in DNA and RNA extracted from the plasma of patients that are similar to alterations found in primary tumor nucleic acids, suggesting that plasma and serum nucleic acids originate in tumor cells (Stroun et al. 1989; Kopreski et al. 1999). Based on this assumption, and as plasma or serum can be a subrogate source of tumor nucleic acids, numerous studies have been carried out to establish the potential clinical and prognostic value of this molecular approach (Chen et al. 1996, 2000; Anker et al. 1997; Lo et al. 1999a, b; Silva et al. 1999, 2001, 2002; Garcia et al. 2006), emphasizing its noninvasive methodology.

However, little is known about the release mechanisms of these molecules from the tumor cells into the bloodstream. 
Apoptosis or necrosis of tumor cells at the tumor site, lysis or apoptosis of circulating tumor cells, or an active release of nucleic acids from the tumor, or even from degenerative normal cells adjacent to tumor cells, are mechanisms put forward to explain the presence of these molecules in the blood (Anker et al. 1999; Jahr et al. 2001). Nevertheless, some questions regarding this process remain enigmatic. It has been determined that about 800 circulating tumor cells per milliliter of blood would be needed to justify the DNA quantities found habitually in plasma from cancer patients (Sorenson 2000), a number that is far greater than has ever been found (Ghossein et al. 1999; Cristofanilli et al. 2004). Several studies on apoptosis showed that plasma DNA often has a ladder pattern after electrophoresis, which is reminiscent of the pattern shown by apoptotic cells (Giacona et al. 1998; Jahr et al. 2001). However, apoptosis is a mechanism that is lost by proliferating tumor cells (Kaufmann and Earnshaw 2000). In tumor necrosis, it has been described that plasma DNA levels decreased considerably in patients with nasopharyngeal carcinomas and with a good response after radiation therapy (Leon et al. 1977), whereas an increase of this molecule would be expected as a result of necrosis induction following radiotherapy. Finally, lymphocytes have been described as spontaneously releasing DNA (Anker et al. 1975), a phenomenon that might occur in human tumor cells. In this way, exosome liberation by different human cells is a known mechanism involved in several cell functions, such as reticulocyte maturation (Rieu et al. 2000), antigen presentation (Wolfers et al. 2001), development of tolerance (Karlsson et al. 2001), and genetic exchange between cells (Valadi et al. 2007). Moreover, RNA-containing vesicles shed by carcinoma cells had already been described in "in vitro assays" (Rosi et al. 1988; Ceccarini et al. 1989; Masella et al. 1989; O’Driscoll 2007).

In this study we tested several molecular approaches for examining the possibility that an important fraction of the mRNA detected in plasma or culture media of tumor cells is highly protected, and that its origin could be an active release mechanism similar to that described for exosome secretion.

\section{RESULTS}

\section{Particle-associated nature of circulating RNA}

The medians of RNAs extracted were: $120 \mathrm{ng} / \mathrm{mL}$ from plasma samples (minimum 47, maximum 236), $81.5 \mathrm{ng} / \mathrm{mL}$ from culture media (minimum 39, maximum 158) from the HT29 cell line, and $90 \mathrm{ng} / \mathrm{mL}$ from culture media from co-culture (minimum 32, maximum 172).

Once the presence of RNA in the plasma sample was confirmed, the incubation processes showed that: (1) After incubation of plasma samples with DEE, all the RNA was captured in the Dynabeads fraction; and (2) after incuba- tion of the plasma with polystyrene beads coated with oligo $\mathrm{dT}$ sequence, the RNA remained in the supernatant plasma. However, when this last plasma sample was previously digested, all RNA was detected in the polystyrene beads fraction (Fig. 1).

Second, we ultracentrifuged two aliquots of plasma samples, one of which had previously undergone a digestion protocol, while the other had not been treated. After extraction of mRNA from the supernatant $(10 \mathrm{~mL})$ and pellet samples, as well as epithelial RNA from supernatant samples $(10 \mathrm{~mL})$, and amplification of succinate dehydrogenase complex subunit A (SDHA) as an indicator of the presence and quality of this RNA, we detected RNA in the pellet only from the sample that was not previously digested and in the supernatant from the digested aliquot (Fig. 2). Additionally, $1 \mu \mathrm{g}$ of RNA from HT29 cell lines, which express liver-specific bHLH-Zip transcription factor (LISCH7), was added to $9 \mathrm{~mL}$ of a donor plasma sample, where no LISCH7 mRNA was previously detected, and to $9 \mathrm{~mL}$ of an RNAase-free water sample. After ultracentrifugation and LISCH7 mRNA amplification from RNA extracted from the pellet and supernatant of each one of the samples, no HT29 RNA was detected either in the supernatant or in the pellet from the plasma sample. HT29 RNA was detected solely in the supernatant from RNAsefree water.

Third, Ber-EP4 antibody expression was found in fresh plasma by flow cytometry, with the positive events being smaller in size and granularity than platelets (defined as the CD41 positive events). However, when a previous preincubation of plasma from the same patients with DEE was performed, no positive events for the Ber-EP4 antibody were observed. In addition to this phenomenon, detectable RNA was present in the aliquot of plasma before microsphere preincubation, while this RNA disappeared after this preincubation. At the same time, we detected RNA in the microsphere fraction (Fig. 3).

Lastly, confocal laser examination of microscope slides containing microspheres showed a monolayer distribution of these structures. Unstained microspheres from both PBS and plasma samples showed slight autofluorescence with the $\mathrm{HeNe}$ (543-nm) excitation laser (Fig. 4A,C). Interestingly, microspheres from plasma samples showed a strong fluorescent signal following cytochemical staining for nucleic acids with propidium iodide (PI) (Fig. 4D). A slight nonspecific signal was observed in microspheres from PBS samples, which are free of associated nucleic acids (Fig. 4B).

\section{Extracellular total RNA is enriched in mRNA and in small RNAs}

In this assay we measured the proportion of mRNA present in the total RNA extracted from cell line HT29 and from the culture media of these cells. The purpose of the assay was to test whether any RNA species are overrepresented in 
A

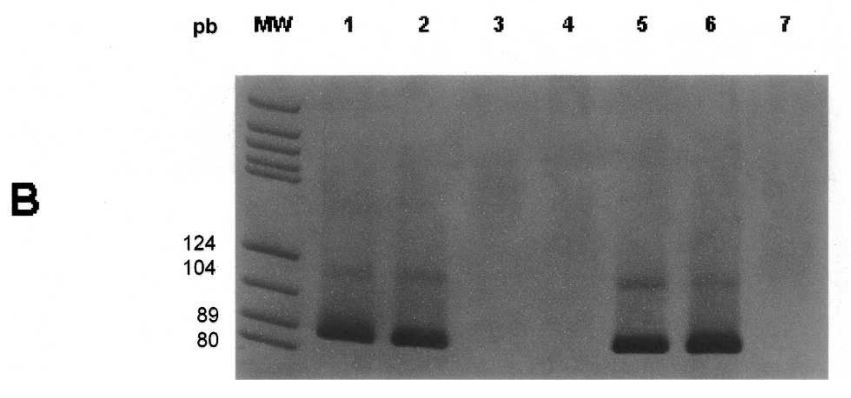

FIGURE 1. (A) Representative outline of the incubation processes of different aliquots from a plasma sample. Step 1, Total RNA extraction; step 2, epithelial RNA extraction after incubation with DEE; step 3, total RNA extraction after withdrawal of DEE microspheres; steps 4 and 6, mRNA extraction after incubation with the Dynabeads mRNA DIRECT kit; steps 5 and 7, total RNA extraction after withdrawal of the oligo dT sequence-coated microspheres. Steps 6 and 7, unlike steps 4 and 5, were carried out after lysis of the plasma sample. (B) Electrophoresis of the SDHA amplification products in each of the previous incubation processes. Each number corresponds to the same number in panel A. DEE, Dynabeads Epithelial Enrich (Epithelial Antigen-coated polystyrene beads); Poli T, polystyrene beads coated with oligo dT sequence; MW, molecular weight marker; magnet symbol, magnetic isolation.

extracellular media, as a possible indicator of the existence of an active release mechanism.

With this objective we first isolated total RNA from the two sources and then isolated the mRNA fraction from the total RNA extracted from the two sources. The total RNA quantification on a NanoDrop ND-1000 Spectrophotometer (NanoDrop Technologies, Inc.) from HT29 cells was $1088 \mathrm{ng} / \mu \mathrm{L}$, and from culture media $(9 \mathrm{~mL})$ was $2.61 \mathrm{ng} / \mu \mathrm{L}$ $(78.3 \mathrm{ng} / \mathrm{mL})$. Subsequent mRNA isolation and quantification showed $15.6 \mathrm{ng} / \mu \mathrm{L}(1.4 \%)$ in the case of HT29 cells and $1.3 \mathrm{ng} / \mu \mathrm{L}(49.8 \%)$ in the case of culture media from these same cells.

We also performed an experiment in which the HT29 cell line was cultured in the presence of human fibroblasts, a situation where the release of exosome-like vesicles is expected, in order to find whether, in addition to this phenomenon, the release of RNA was also affected. $\mathrm{LISCH} 7$, which is expressed in epithelial cells and that IMR90 fails to express, was used as a marker for the presence of RNA of epithelial origin in the culture media. We observed a $17.47 \%$ LISCH7 mRNA expression increase in the HT29 cell line in the presence of fibroblasts. However, the LISCH7 mRNA increase reached $74.67 \%$ in the culture media from the coculture, compared with the culture media from the HT29 cell line growing alone (Fig. 5).

Finally, after analysis in a bioanalyzer to assess the RNA samples extracted from the HT29 cell line and from plasma from a colon cancer patient, we observed the expected pattern for RNA from the cell line; while in the plasma sample, a large amount of small RNA was detected, as well as a comparatively very low amount of ribosomal RNA, as has been previously described (Valadi et al. 2007; Fig. 6).

\section{DISCUSSION}

In this study we subjected plasma and culture media samples to various RNA extraction protocols in order to analyze the nature and origin of these molecules. At the same time, these processes were accompanied by imaging techniques, such as confocal microscopy and flow cytometry. After this, the results suggest that most, if not all, of the RNA detected in plasma as free nucleic acids could be protected.

We show that, after incubation of plasma or culture media samples with super-paramagnetic beads coated with an epithelial antibody, all the mRNA detected is joined to these microspheres through putative epithelial antigens, demonstrating their particle-associated nature. Moreover, after this assay in plasma samples, we did not detect RNA that was not joined to the microspheres. In other words, all the RNA in this sample is epithelial-marker related. Furthermore, in the confocal study, small rounded masses of amorphous material, 1 - to $2-\mu \mathrm{m}$ in diameter, were joined to the DEE after PI staining, when the plasma sample was incubated with these microspheres. These vesicles were not observed without PI marking in plasma samples, and they were never found, with or without PI marking, in PBS incubated with microspheres. These results support the presence of complexes formed by nucleic acids 


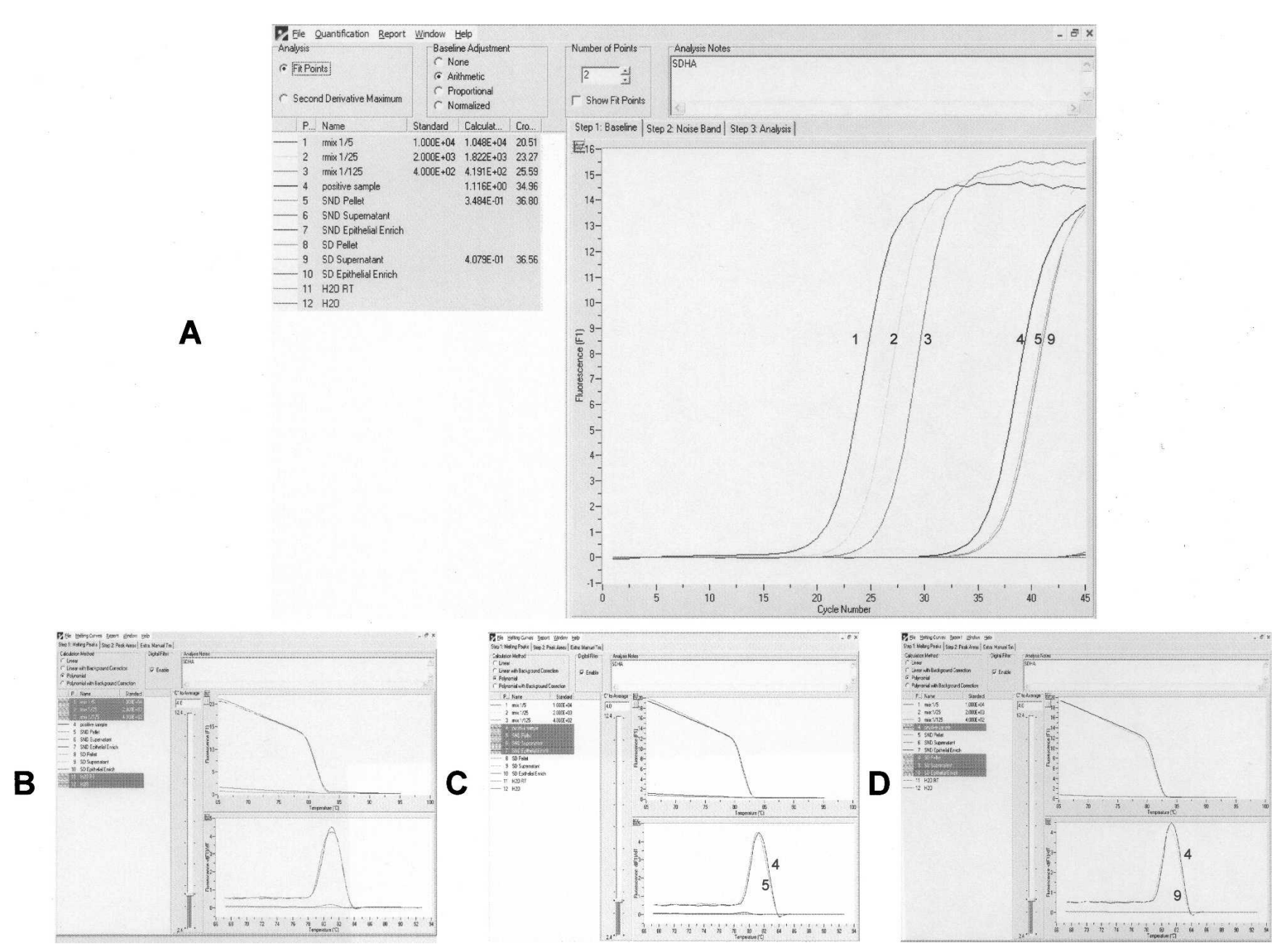

FIGURE 2. SDHA real-time PCR results from the ultracentrifugation assay. "Pellet" represents mRNA extraction from the pellet after ultracentrifugation; "Supernatant" represents mRNA extraction from the supernatant after ultracentrifugation; and "Epithelial Enrich" represents epithelial RNA extraction from the supernatant after ultracentrifugation. Before ultracentrifugation, one of the samples was subjected to lysis (SD, sample digested), whereas the other was not (SND, sample non-digested). (A) Fluorescence acquisition. (B) Melting curves from serial dilution of cDNA (1-3) and positive sample (4). (C) Melting curves from positive sample (4) and non-digested samples (5). (D) Melting curves from the positive sample (4) and digested samples (9). Retro-transcription of an $\mathrm{H}_{2} \mathrm{O}$ sample $\left(\mathrm{H}_{2} \mathrm{O}\right.$ RT), or an $\mathrm{H}_{2} \mathrm{O}$ sample was used directly as a negative control $\left(\mathrm{H}_{2} \mathrm{O}\right)$.

and, at least, by some membrane glycopeptides, molecules that are specifically joined to the DEE. Moreover, based on their size characteristics, those masses observed in the confocal microscopy assay do not look like apoptotic bodies or cellular remains coming from degenerative processes such as necrosis or lysis mechanisms. Additionally, the results after ultracentrifugation processes show that RNA as free nucleic acid is soon degraded in plasma and cannot be plated by ultracentrifugation, results that support the view that RNA extracted from plasma or culture media must be protected in the multiparticle complex.

Indeed, the particle-associated nature of these molecules was postulated by $\mathrm{Ng}$ et al. (2002), who demonstrated that, after filtration of a plasma sample through filters with different pore sizes, the quantity of filterable RNA diminishes in accord with the reduction in size of the pore.
Similar results were obtained by these investigators when the plasma sample was ultracentrifuged. However, in this experiment $\mathrm{Ng}$ et al. (2002) still found small quantities of mRNA in the supernatant samples, whereas we did not find traces of it, except when the hypothetical protective structures were degraded; this is probably due to differences in technical approaches.

Finally, we showed that this particle-associated RNA is mRNA enriched. Indeed, we observed that the mRNA proportion of the total RNA extracted from culture media $(49.8 \%)$ was considerably bigger than the mRNA proportion found in the total RNA extracted from our own cells of the culture (1.4\%); whereas a similar ratio would be expected if the extracellular RNA found in the culture media came from a passive release mechanism such as any cellular death mechanism. This argued in favor of an active release 

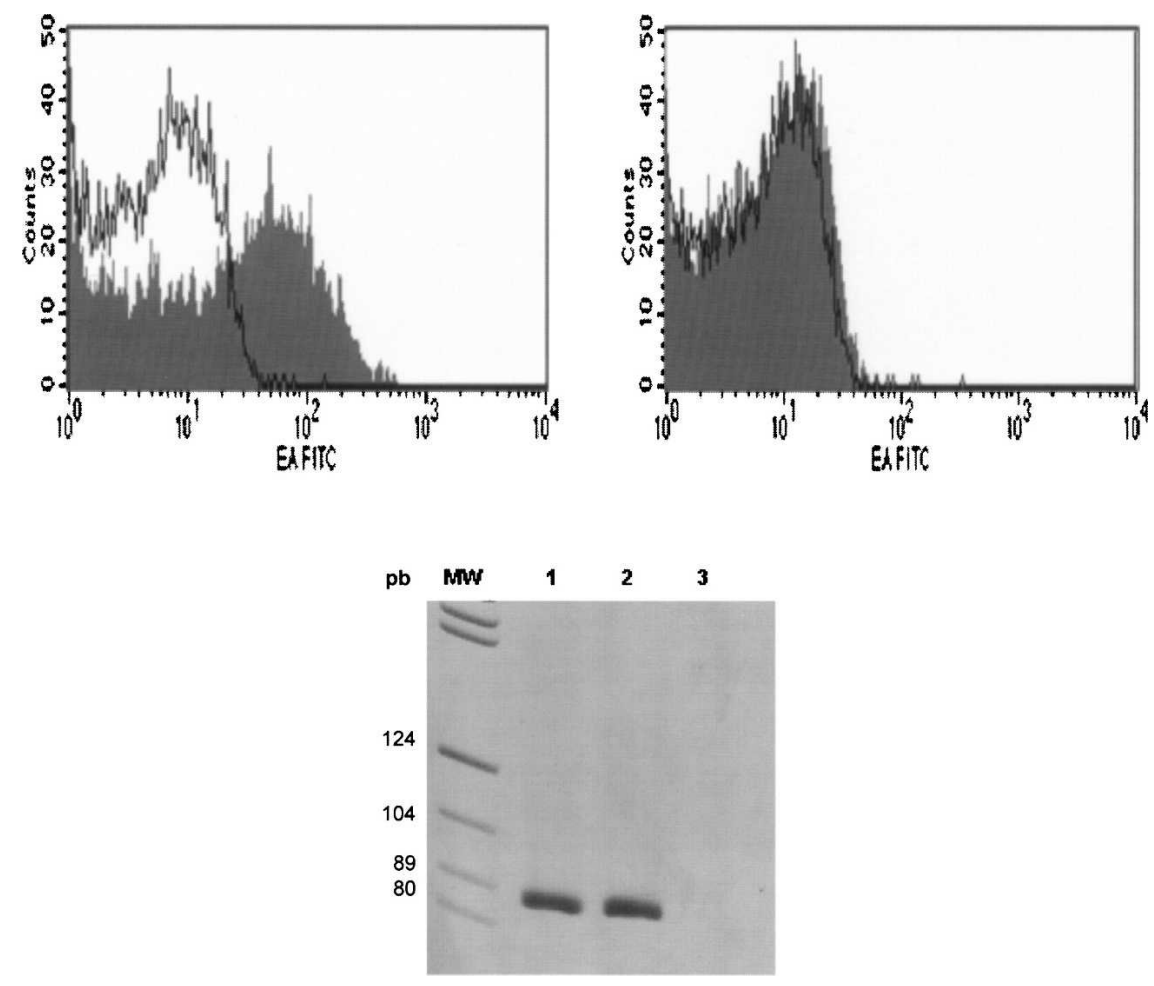

FIGURE 3. (Left panel) FACS analyses of plasma incubated with monoclonal antibody mouse anti-human epithelial antigen, clone Ber-EP4, filled trace, prior to DEE incubation or after incubation and withdrawal DEE (right panel). A mouse IgG1-FITC irrelevant Ab was used as a negative control of staining in both cases (open trace). (Bottom panel) SDHA real-time PCR results from RNA extracted from plasma before incubation with DEE (lane 1), DEE fraction (lane 2), and plasma after incubation and withdrawal DEE (lane 3).

mechanism. In addition, we found more LISCH7 mRNA copies or, alternatively, fewer mRNA copies of the housekeeping gene outside the cell than inside it. In summary, there was unbalanced distribution of the two genes, which can be explained, again, only by the existence of a differential release mechanism. Moreover, tumor cells actively recruit stromal cells, such as inflammatory cells, vascular cells, and fibroblasts, into the tumor. This recruitment is essential for the generation of a microenvironment that actively fosters tumor growth (Bhowmick et al. 2004a,b), wherein the intestinal epithelial cells release exosome-like vesicles (van Niel et al. 2001). In our study, the relative increment of LISCH7 mRNA levels over SDHA mRNA levels in the culture media is evident when HT29 cells are in the presence of fibroblasts, suggesting the existence of a possible release mechanism that is stimulated under determined microenvironmental conditions. Finally, the bioanalyzer analyses showed that the RNA extracted from a plasma sample is enriched in small RNAs, which, as in the previous mRNA enrichment demonstration, is consistent with the findings of Valadi et al., who tested it in mouse and human mast cell lines (Valadi et al. 2007).

Our results lead us to believe that these molecules are highly protected and that such materials are actively released, without discarding the existence of other sources such as necrosis, lysis, or apoptosis (Jahr et al. 2001). In the future, it will be important to establish the proportion of free nucleic acids coming from cellular death mechanisms, as an indicator of good prognosis, and those coming from an active release mechanism, expressing the activity and proliferation capacity of the tumor and, as a consequence, serving as a hypothetical poor prognosis factor.

\section{MATERIALS AND METHODS}

\section{Plasma samples}

Seven patients diagnosed with colon adenocarcinoma were recruited sequentially in our Medical Oncology Department before surgery, and $20 \mathrm{~mL}$ of blood was taken from each for this study. A blood sample from a healthy donor was also obtained at the hematology unit of our hospital. They were informed about its nature and gave their informed consent, as recommended by the Research Ethics Board of our hospital, which approved the study.

To obtain plasma and supernatant culture media free of cells, blood and cell culture media were centrifuged at $300 \mathrm{~g}$ for $10 \mathrm{~min}$. A second centrifugation to $2000 \mathrm{~g}$ for $20 \mathrm{~min}$ to eliminate remaining cells was performed. All centrifugation steps were carried out at $4^{\circ} \mathrm{C}$. After determination of SDHA mRNA in plasma (see below), we found amplifiable RNA in six of the seven patients: Two of them were used in ultracentrifugation experiments, while the four remaining patients were used for subsequent analyses. Finally, the samples were divided into aliquots and processed immediately without freezing. Plasma from the healthy donor was used in the assay performed to prove the stability of the hypothetical free RNA in a sample of these characteristics.

\section{Culture media}

The HT29 cell line and IMR90 fibroblasts were cultured at $37^{\circ} \mathrm{C}$ in Dulbecco modified Eagle medium (DMEM; Gilco Life Technologies) containing $10 \%$ heat-inactivated fetal calf serum (FCS), $2 \mathrm{mM}$ L-glutamine (Invitrogen), penicillin (100 units/mL), streptomycin $(100 \mathrm{ng} / \mathrm{mL})$, and fungizone $(0.25 \mu \mathrm{g} / \mathrm{mL})$ in a humidified atmosphere of $5 \% \mathrm{CO}_{2}, 95 \%$ air. For co-culture, $2 \times 10^{5}$ HT29 cells and $4 \times 10^{5}$ IMR90 fibroblasts were mixed and seeded under the conditions previously explained. Under these conditions and after $4 \mathrm{~d}$, the co-cultures achieved confluence at $80 \%$ in a 3:1 ratio of fibroblasts:HT29. At this point, the HT29 cells and IMR90 fibroblasts were released from the culture tissue plate by trypsinization, and then the epithelial cells were isolated from fibroblasts using DEE (Pena et al. 2005). Finally, RNA was extracted from HT29 and fibroblasts growing alone or in 

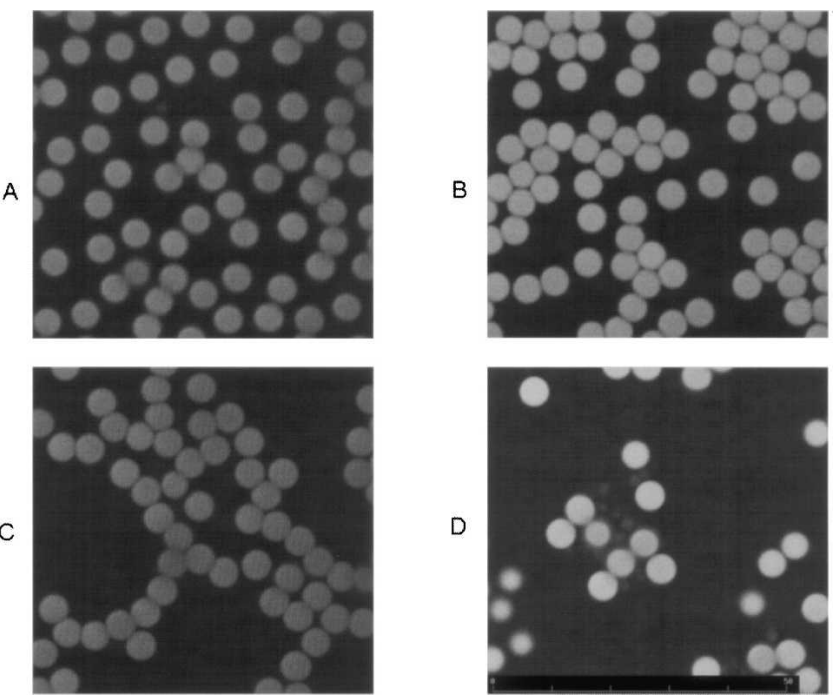

FIGURE 4. Result of confocal laser examination of different samples incubated in the presence of super-paramagnetic polystyrene beads coated with Ber-EP4 Ab. (A) PBS without staining with propidium iodide (PI). (B) The same sample stained with PI. (C) Plasma from a colon cancer patient without PI staining. $(D)$ The same sample stained with PI, showing small masses in the vicinity of the microbeads.

co-culture as well as from their respective culture media. This assay was repeated four times.

\section{Protocols of RNA extraction}

Total RNA from plasma or culture media samples was extracted using a commercial kit (RNeasy Mini Kit; Qiagen, Inc.) according to the manufacturer's protocol (isolation of total RNA from animal cells) but with the following modifications: Each milliliter of sample was mixed with $200 \mu \mathrm{L}$ of buffer RLT and $2 \mu \mathrm{L}$ of $\beta$-mercaptoethanol; the mixture was vortexed for $30 \mathrm{sec}$; it was finally mixed with a volume of $70 \%$ ethanol and applied to an RNeasy mini-column in aliquots of $700 \mu \mathrm{L}$, following the manufacturer's protocol. Total RNA was eluted in $30 \mu \mathrm{L}$ of RNase-free water per milliliter of processed sample. Total RNA from the cell line was extracted in line with the manufacturer's protocol in the same commercial kit for isolation of total RNA from animal cells.

For epithelial RNA extraction, we first subjected each milliliter of plasma and culture media to an incubation with super-paramagnetic polystyrene beads coated with the Ber-EP4 antibody (Ab), as described above. Then, these polystyrene beads were magnetically separated from the rest of the sample and processed according to the protocol for isolation of total RNA from animal cells (RNeasy Mini Kit; Qiagen, Inc.). Total RNA was eluted in $30 \mu \mathrm{L}$ of RNase-free water per milliliter of processed sample. For the Bioanalyzer assay, total RNA, small RNA included, was extracted according to recommendations for total RNA extraction in the mirVana miRNA isolation kit (Ambion, Inc.).

Specific extraction of mRNA from plasma and culture media was performed by incubation of the samples with super-paramagnetic polystyrene beads coated with oligo dT sequence, and processed according to the manufacturer's protocol for viral poly $\mathrm{A}^{+}$RNA isolation (Dynabeads mRNA DIRECT kit; Dynal Bio- tech). Finally, mRNA was eluted in $30 \mu \mathrm{L}$ of $10 \mathrm{mM}$ Tris- $\mathrm{HCl}$ per milliliter of processed sample. After ultracentrifugation, the pellet was treated according to the manufacturer's protocol for cultured cells and cell suspensions (Dynabeads mRNA DIRECT kit; Dynal Biotech) and finally eluted in $30 \mu \mathrm{L}$ of $10 \mathrm{mM}$ Tris- $\mathrm{HCl}$.

\section{Ultracentrifugation}

Once cells were eliminated and the presence of RNA in plasma was demonstrated, as stated, $9 \mathrm{~mL}$ of plasma sample from two colon cancer patients was first mixed and then divided into two aliquots. The first aliquot was digested with $9 \mathrm{~mL}$ of RLN buffer (50 mM Tris-Cl, pH 8.0; $140 \mathrm{mM} \mathrm{NaCl} ; 1.5 \mathrm{mM} \mathrm{MgCl}_{2} ; 0.5 \%$ [v/ v] Nonidet P-40 [1.06 g/mL]) and adjusted with RNase-free water to a $20-\mathrm{mL}$ final volume. The second aliquot was directly adjusted to $20 \mathrm{~mL}$ with RNase-free water. Both samples were ultracentrifuged at $65,000 \mathrm{~g}$ for $2.5 \mathrm{~h}$ using a Beckman Type-70 Ti (Beckman Coulter). After ultracentrifugation, mRNA from the pellet and supernatant samples, as well as epithelial RNA from supernatant samples, were extracted as described in the section on Protocols of RNA extraction. In an additional assay, $1 \mu \mathrm{g}$ of RNA from the HT29 cell line was added to $9 \mathrm{~mL}$ of donor plasma sample and to $9 \mathrm{~mL}$ of RNAase-free water and subjected to the same ultracentrifugation conditions.

\section{QRT-PCR}

Liver-specific bHLH-Zip transcription factor (LISCH7) mRNA expression in each sample was measured as a ratio against the expression of one reference housekeeping gene, succinate dehydrogenase complex subunit A (SDHA). The relative concentrations of the target and the reference gene were calculated by interpolation, using a standard curve of each gene plotted from the same serial dilution of cDNA from positive tumor tissue. SDHA was amplified to test the presence of RNA. For the

A

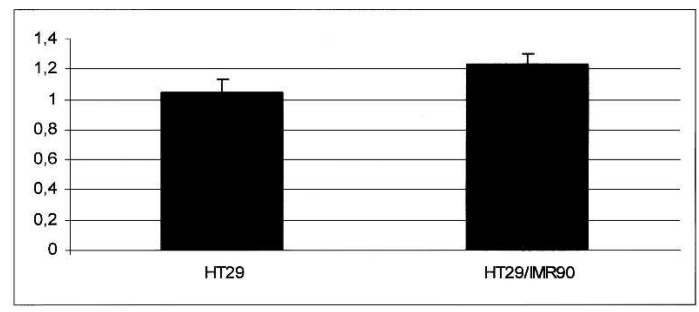

B

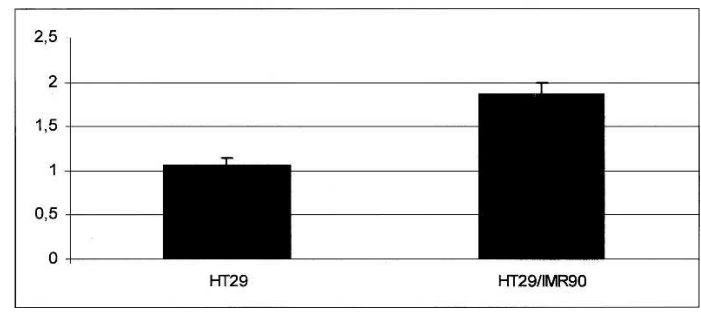

FIGURE 5. LISCH7 mRNA levels in HT29 cells growing alone or in the presence of IMR90 fibroblasts $(A), 14.7 \%$ increase; or their respective culture media $(B), 74.67 \%$ increase. Standardized mean values and standard deviations obtained in four independent experiments are shown. 
HT29

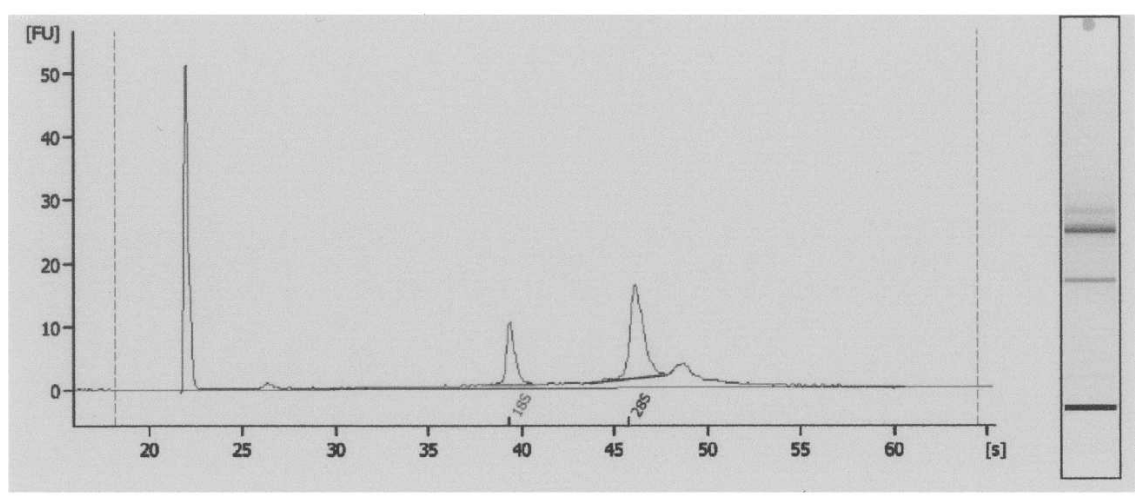

PLASMA

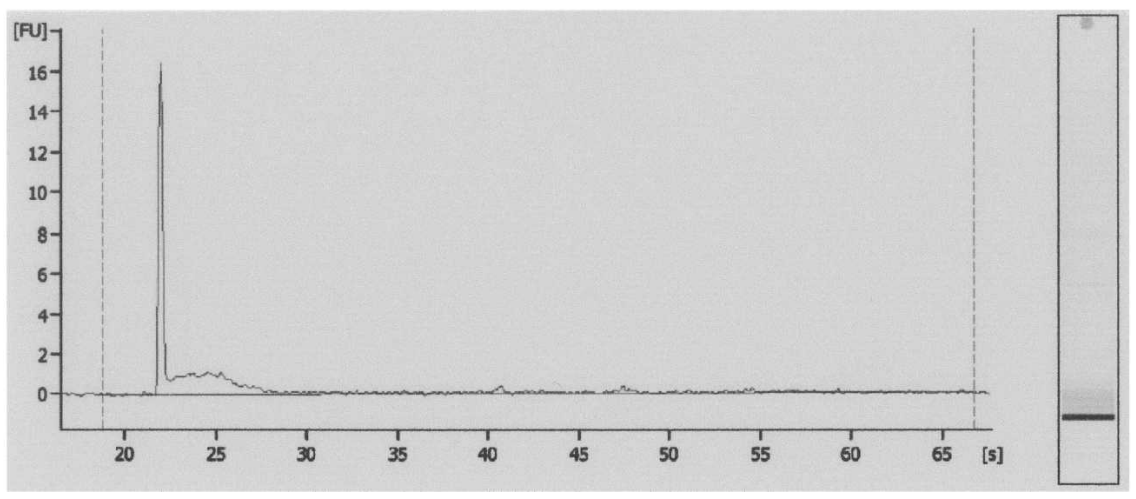

FIGURE 6. (Top panel) RNA from the HT29 cell line and from plasma from colon cancer patients, detected using a bioanalyzer. (Bottom panel) No or very low ribosomal RNA levels are present in the RNA from the plasma sample, as well as more small RNAs than in the RNA obtained from HT29 cell line.

synthesis of cDNA, RNA was retro-transcribed using the Gold RNA PCR Core Kit (PE Biosystems), according to the manufacturer's instructions. Random hexamers were used as primers for cDNA synthesis.

Real-time PCR was performed in a Light-Cycler apparatus (Roche Diagnostics), using the LightCycler-FastStart ${ }^{\text {PLUS }}$ DNA Master SYBR Green I Kit (Roche Diagnostics), according to the manufacturer's instructions.

The primers used were: SDHA- 5'-TGGGAACAAGAGGGCA TCTG-3' forward (F) and 5'-CCACCACTGCATCAAATTCATG$3^{\prime}$ reverse (R); LISCH7- 5'-GCCAAGGCTCCTATGTACCC-3'F and $5^{\prime}$-CCTGAATCCTGTAGCCACTGC- $3^{\prime} \mathrm{R}$. The annealing temperatures were $59^{\circ} \mathrm{C}$. At the end of the PCR cycles, melting curve analyses were performed to confirm the generation of the specific PCR product expected. The PCR products were sequenced in an ABI Prism 377 DNA sequencer apparatus (PE Applied Biosystems).

\section{Gel electrophoresis detection}

The final $10 \mu \mathrm{L}$ of the PCR product was mixed with $3 \mu \mathrm{L}$ of loading buffer $(0.02 \%$ xylene cyanol and $0.02 \%$ bromophenol blue) for a total volume $13 \mu \mathrm{L}$. Electrophoresis was run on nondenaturing $8 \%$ polyacrylamide gels for $2 \mathrm{~h}$ at $500 \mathrm{~V}$. After gel electrophoresis, band intensity was detected by a non-radioisotopic technique using a commercially available silver-staining method (Oto et al. 1993).

\section{Incubation processes}

The plasma samples from three patients with positive plasma RNA were divided into three aliquots (2 $\mathrm{mL}$ each). One aliquot of each patient was incubated with $15 \mu \mathrm{L}$ of superparamagnetic polystyrene beads coated with Ber-EP4 (antibody specific for two glycopolypeptide membrane antigens expressed in most normal and neoplastic human epithelial tissues [Dynabeads Epithelial Enrich; $1.5 \times 10^{6}$ beads in PBS/0.1\% BSA $/ 0.6 \%$ Na Citrate; Dynal Biotech ASA]) per milliliter of plasma for $20 \mathrm{~min}$, in line with the Dynabeads Epithelial Enrich (DEE) protocol. After this process, epithelial RNA was extracted from the Dynabeads fraction by magnetic separation, and total RNA was extracted from the remaining plasma with the RNeasy Mini Kit protocol, as described above in the Protocols of RNA extraction.

A second aliquot of each was incubated with $15 \mu \mathrm{L}$ of super-paramagnetic polystyrene beads ( $\sim 5 \mathrm{mg} / \mathrm{mL}$ in phosphate-buffered saline, PBS) coated with oligo dT sequence, Dynabeads mRNA DIRECT kit (Dynal Biotech), per milliliter of plasma. After incubation, mRNA was extracted from magnetically separated microspheres, and the total RNA was extracted from the remaining plasma as described above.

Finally, the third aliquot of each was processed like the second aliquot was, but, prior to incubation, digestion with the lysis buffer of the Dynabeads mRNA DIRECT kit was added, according to the manufacturer's protocol.

These processes are outlined in Figure 1.

\section{Bioanalyzer}

Total RNA, including small RNA, extracted from the plasma sample after incubation with DEE and from the HT29 cell line, was analyzed using an Agilent 2100 Bioanalyzer (http://www.chem. agilent.com) equipped with an RNA 6000 pico LabChip kit, following the manufacturer's recommendations.

\section{Flow cytometry}

One aliquot of $100 \mu \mathrm{L}$ of plasma sample of each of the three previous patients was preincubated with super-paramagnetic polystyrene beads coated with Ber-EP4 Ab, as described in the Incubation processes. After this preincubation time, the polystyrene beads were magnetically separated. Then this plasma sample, together with another $100 \mu \mathrm{L}$ of plasma sample from 
the same patients, none of them subjected to the previous process, were incubated with $10 \mu \mathrm{L}$ of monoclonal antibody mouse antihuman epithelial antigen, clone Ber-EP4 (DAKO Cytomation), conjugated with fluorescein isothiocyanate (FITC), for $20 \mathrm{~min}$ at room temperature (RT). A mouse IgG1-FITC irrelevant $\mathrm{Ab}$ was used as a negative control of staining. Plasma samples in both conditions were also labeled with a phycoerythrin (PE)-conjugated anti-CD41 monoclonal $\mathrm{Ab}$ that was specific for platelets. Labeled samples were then analyzed in a FACScalibur flow cytometer with CellQuest software (BD Biosciences). Forward and side-scatter parameters were set to logarithmic amplification, and events smaller than the CD41-positive cells were analyzed.

Simultaneously, total RNA extractions of plasma samples and epithelial RNA from magnetically separated Dynabeads Epithelial Enrich were done in each patient.

The epithelial Ab used here, Ber-EP4, can be obtained under two formats: free, or incorporated to microspheres. Thus, to ensure specificity of the two Ab forms, the cell lines used in this study, HT29 cells and IMR90 fibroblasts, were incubated with free $\mathrm{Ab}$ (DAKO Cytomation) or with a mouse IgG1-FITC irrelevant Ab for 20 min at RT. After this, HT29 cells and IMR90 fibroblasts were incubated with DEE, microbeads coated with Ber-EP4 Ab. As a control, HT29 cells and IMR90 fibroblasts were directly incubated with DEE without previous incubation with free BerEP4 Ab. DEE did not join IMR90 fibroblasts under any conditions, but specific binding of HT29, not previously incubated with free Ber-EP4, was observed. After incubation with free $\mathrm{Ab}$ and as a result of epithelial antigen blockage, the DEE did not bind HT29 cells. This result shows that both forms of Ber-EP4 Ab have affinity for the same epithelial marker.

\section{Confocal microscopy}

Both $100 \mu \mathrm{L}$ of PBS and $100 \mu \mathrm{L}$ of plasma from the same patients incubated with super-paramagnetic polystyrene beads coated with the Ber-EP4 Ab were cytospin-fixed and marked with propidium iodide (PI). Samples containing microspheres were centrifuged with cytospin to fix microspheres to microscope slides. Then, these slides were fixed with $3.7 \%$ paraformaldehyde in PBS and washed in PBS for $15 \mathrm{~min}$ at RT. Some microscope slide preparations containing microspheres were stained with PI $(2.5 \times$ $10^{-4} \mu \mathrm{g} / \mathrm{mL}$ ), a fluorescent cytochemical staining for nucleic acids, for $10 \mathrm{~min}$ at RT. All microscope slide preparations were mounted with the antifading medium Vectashield (Vector) and were examined with a BioRad 1024 confocal laser microscope, equipped with a $\mathrm{HeNe}$ laser $(543 \mathrm{~nm})$ to arouse PI staining. Images were recorded using a $63 \times(1.4 \mathrm{NA})$ PlanApochromat (c. Zeiss Microimaging, Inc.) objective and with the same confocal settings. TIFF images were transferred to Adobe Photoshop 7.0 software for processing and presentation (Fig. 4).

\section{ACKNOWLEDGMENTS}

We thank Drs. M. Lafarga and M. Berciano for their help with confocal laser microscopy analysis, and Michael Eaude for correcting the English. This study was supported by Grants from the Ministerio de Educación y Ciencia (SAF2004-01002) and the Fundación de Investigación Médica Mutua Madrileña.

Received July 25, 2007; accepted March 17, 2008.

\section{REFERENCES}

Anker, P., Stroun, M., and Maurice, P.A. 1975. Spontaneous release of DNA by human blood lymphoctyes as shown in an in vitro system. Cancer Res. 35: 2375-2382.

Anker, P., Lefort, F., Vasioukhin, V., Lyautey, J., Lederrey, C., Chen, X.Q., Stroun, M., Mulcahy, H.E., and Farthing, M.J. 1997. $\mathrm{K}$-ras mutations are found in DNA extracted from the plasma of patients with colorectal cancer. Gastroenterology 112: 1114-1120.

Anker, P., Mulcahy, H., Chen, X.Q., and Stroun, M. 1999. Detection of circulating tumour DNA in the blood (plasma/serum) of cancer patients. Cancer Metastasis Rev. 18: 65-73.

Bhowmick, N.A., Chytil, A., Plieth, D., Gorska, A.E., Dumont, N., Shappell, S., Washington, M.K., Neilson, E.G., and Moses, H.L. 2004a. TGF- $\beta$ signaling in fibroblasts modulates the oncogenic potential of adjacent epithelia. Science 303: 848-851.

Bhowmick, N.A., Neilson, E.G., and Moses, H.L. 2004b. Stromal fibroblasts in cancer initiation and progression. Nature 432: 332337.

Ceccarini, M., Guidoni, L., Luciani, A.M., Mariutti, G., Rosi, A., and Viti, V. 1989. Biochemical and NMR studies on structure and release conditions of RNA containing vesicles shed by human colon adenocarcinoma cells. Int. J. Cancer 44: 714-721.

Chen, X.Q., Stroun, M., Magnenat, J.L., Nicod, L.P., Kurt, A.M., Lyautey, J., Lederrey, C., and Anker, P. 1996. Microsatellite alterations in plasma DNA of small cell lung cancer patients. Nat. Med. 2: 1033-1035.

Chen, X.Q., Bonnefoi, H., Pelte, M.F., Lyautey, J., Lederrey, C., Movarekhi, S., Schaeffer, P., Mulcahy, H.E., Meyer, P., Stroun, M., et al. 2000. Telomerase RNA as a detection marker in the serum of breast cancer patients. Clin. Cancer Res. 6: 38233826.

Cristofanilli, M., Budd, G.T., Ellis, M.J., Stopeck, A., Matera, J., Miller, M.C., Reuben, J.M., Doyle, G.V., Allard, W.J., Terstappen, L.W., et al. 2004. Circulating tumor cells, disease progression, and survival in metastatic breast cancer. N. Engl. J. Med. 351: 781-791.

Fournie, G.J., Martres, F., Pourrat, J.P., Alary, C., and Rumeau, M. 1993. Plasma DNA as cell death marker in elderly patients. Gerontology 39: 215-221.

Garcia, J.M., Garcia, V., Silva, J., Peña, C., Dominguez, G., Sanchez, A., Sanfrutos, L., Provencio, M., Millan, I., Chaparro, D., et al. 2006. Extracellular tumor DNA in plasma and overall survival in breast cancer patients. Genes Chromosomes Cancer 45: 692-701.

Ghossein, R.A., Bhattacharya, S., and Rosai, J. 1999. Molecular detection of micrometastases and circulating tumor cells in solid tumors. Clin. Cancer Res. 5: 1950-1960.

Giacona, M.B., Ruben, G.C., Iczkowski, K.A., Roos, T.B., Porter, D.M., and Sorenson, G.D. 1998. Cell-free DNA in human blood plasma: Length measurements in patients with pancreatic cancer and healthy controls. Pancreas 17: 89-97.

Jahr, S., Hentze, H., Englisch, S., Hardt, D., Fackelmayer, F.O., Hesch, R.D., and Knippers, R. 2001. DNA fragments in the blood plasma of cancer patients: Quantitations and evidence for their origin from apoptotic and necrotic cells. Cancer Res. 61: 16591665.

Karlsson, M., Lundin, S., Dahlgren, U., Kahu, H., Pettersson, I., and Telemo, E. 2001. "Tolerosomes" are produced by intestinal epithelial cells. Eur. J. Immunol. 31: 2892-2900.

Kaufmann, S.H. and Earnshaw, W.C. 2000. Induction of apoptosis by cancer chemotherapy. Exp. Cell Res. 256: 42-49.

Koffler, D., Agnello, V., Winchester, R., and Kunkel, H.G. 1973. The occurrence of single-stranded DNA in the serum of patients with systemic lupus erythematosus and other diseases. J. Clin. Invest. 52: 198-204.

Kopreski, M.S., Benko, F.A., Kwak, L.W., and Gocke, C.D. 1999. Detection of tumor messenger RNA in the serum of patients with malignant melanoma. Clin. Cancer Res. 5: 1961-1965. 
Leon, S.A., Shapiro, B., Sklaroff, D.M., and Yaros, M.J. 1977. Free DNA in the serum of cancer patients and the effect of therapy. Cancer Res. 37: 646-650.

Leon, S.A., Revach, M., Ehrlich, G.E., Adler, R., Petersen, V., and Shapiro, B. 1981. DNA in synovial fluid and the circulation of patients with arthritis. Arthritis Rheum. 24: 1142-1150.

Lo, Y.M., Chan, L.Y., Lo, K.W., Leung, S.F., Zhang, J., Chan, A.T., Lee, J.C., Hjelm, N.M., Johnson, P.J., and Huang, D.P. 1999a. Quantitative analysis of cell-free Epstein-Barr virus DNA in plasma of patients with nasopharyngeal carcinoma. Cancer Res. 59: 1188-1191.

Lo, K.W., Lo, Y.M., Leung, S.F., Tsang, Y.S., Chan, L.Y., Johnson, P.J., Hjelm, N.M., Lee, J.C., and Huang, D.P. 1999b. Analysis of cell-free Epstein-Barr virus associated RNA in the plasma of patients with nasopharyngeal carcinoma. Clin. Chem. 45: $1292-1294$

Mandel, P. and Métais, P. 1948. Les acides nucléiques du plasma sanguin chez I'Homme. C.R. Acad. Sci. Paris 142: 241-243.

Masella, R., Cantafora, A., Guidoni, L., Luciani, A.M., Mariutti, G., Rosi, A., and Viti, V. 1989. Characterization of vesicles, containing an acylated oligopeptide, released by human colon adenocarcinoma cells. FEBS Lett. 246: 25-29.

Ng, E.K., Tsui, N.B., Lam, N.Y., Chiu, R.W., Yu, S.C., Wong, S.C., Lo, E.S., Rainer, T.H., Johnson, P.J., and Lo, Y.M. 2002. Presence of filterable and nonfilterable mRNA in the plasma of cancer patients and healthy individuals. Clin. Chem. 48: 1212-1217.

O'Driscoll, L. 2007. Extracellular nucleic acids and their potential as diagnostic, prognostic and predictive biomarkers. Anticancer Res. 27: 1257-1265.

Oto, M., Miyake, S., and Yuasa, Y. 1993. Optimization of nonradioisotopic single strand conformation polymorphism analysis with a conventional minislab gel electrophoresis apparatus. Anal. Biochem. 213: 19-22.

Peña, C., Garcia, J.M., Silva, J., Garcia, V., Rodríguez, R., Alonso, I., Millan, I., Salas, C., de Herreros, A.G., Munoz, A., et al. 2005. Ecadherin and vitamin D receptor regulation by SNAIL and ZEB1 in colon cancer: Clinicopathological correlations. Hum. Mol. Genet. 14: 3361-3370.

Rieu, S., Géminard, C., Rabesandratana, H., Sainte-Marie, J., and Vidal, M. 2000. Exosomes released during reticulocyte maturation bind to fibronectin via integrin $\alpha 4 \beta 1$. Eur. J. Biochem. 267: 583 590 .
Rosi, A., Guidoni, L., Luciani, A.M., Mariutti, G., and Viti, V. 1988. RNA-lipid complexes released from the plasma membrane of human colon carcinoma cells. Cancer Lett. 39: 153-160.

Shapiro, B., Chakrabarty, M., Cohn, E.M., and Leon, S.A. 1983. Determination of circulating DNA levels in patients with benign or malignant gastrointestinal disease. Cancer 51: 2116-2120.

Silva, J.M., Dominguez, G., Garcia, J.M., Gonzalez, R., Villanueva, M.J., Navarro, F., Provencio, M., San Martin, S., Espana, P., and Bonilla, F. 1999. Presence of tumor DNA in plasma of breast cancer patients: Clinicopathological correlations. Cancer Res. 59: 3251-3256.

Silva, J.M., Dominguez, G., Silva, J., Garcia, J.M., Sanchez, A., Rodriguez, O., Provencio, M., Espana, P., and Bonilla, F. 2001. Detection of epithelial messenger RNA in the plasma of breast cancer patients is associated with poor prognosis tumor characteristics. Clin. Cancer Res. 7: 2821-2825.

Silva, J.M., Rodríguez, R., Garcia, J.M., Munoz, C., Silva, J., Domínguez, G., Provencio, M., Espana, P., and Bonilla, F. 2002. Detection of epithelial tumour RNA in the plasma of colon cancer patients is associated with advanced stages and circulating tumour cells. Gut 50: 530-534.

Sorenson, G.D. 2000. Detection of mutated KRAS2 sequences as tumor markers in plasma/serum of patients with gastrointestinal cancer. Clin. Cancer Res. 6: 2129-2137.

Stroun, M., Anker, P., Maurice, P., Lyautey, J., Lederrey, C., and Beljanski, M. 1989. Neoplastic characteristics of the DNA found in the plasma of cancer patients. Oncology 46: 318-322.

Tan, E.M., Schur, P.H., Carr, R.I., and Kunkel, H.G. 1966. Deoxybonucleic acid (DNA) and antibodies to DNA in the serum of patients with systemic lupus erythematosus. J. Clin. Invest. 45: 1732-1740.

Valadi, H., Ekstrom, K., Bossios, A., Sjostrand, M., Lee, J.J., and Lotvall, J.O. 2007. Exosome-mediated transfer of mRNAs and microRNAs is a novel mechanism of genetic exchange between cells. Nat. Cell Biol. 9: 654-659.

van Niel, G., Raposo, G., Candalh, C., Boussac, M., Hershberg, R., Cerf-Bensussan, N., and Heyman, M. 2001. Intestinal epithelial cells secrete exosome-like vesicles. Gastroenterology 121: 337-349.

Wolfers, J., Lozier, A., Raposo, G., Regnault, A., Thery, C., Masurier, C., Flament, C., Pouzieux, S., Faure, F., Tursz, T., et al. 2001. Tumor-derived exosomes are a source of shared tumor rejection antigens for CTL cross-priming. Nat. Med. 7: 297-303. 

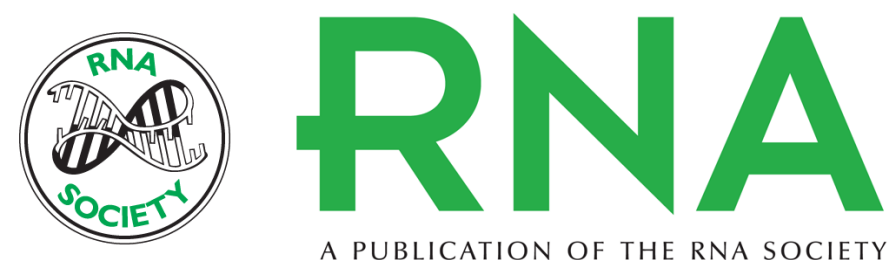

A PUBLICATION OF THE RNA SOCIETY

\section{Extracellular plasma RNA from colon cancer patients is confined in a vesicle-like structure and is mRNA-enriched}

José Miguel García, Vanesa García, Cristina Peña, et al.

RNA 2008 14: 1424-1432

References This article cites 40 articles, 15 of which can be accessed free at: http://rnajournal.cshlp.org/content/14/7/1424.full.html\#ref-list-1

License

Email Alerting Receive free email alerts when new articles cite this article - sign up in the box at the Service top right corner of the article or click here. 